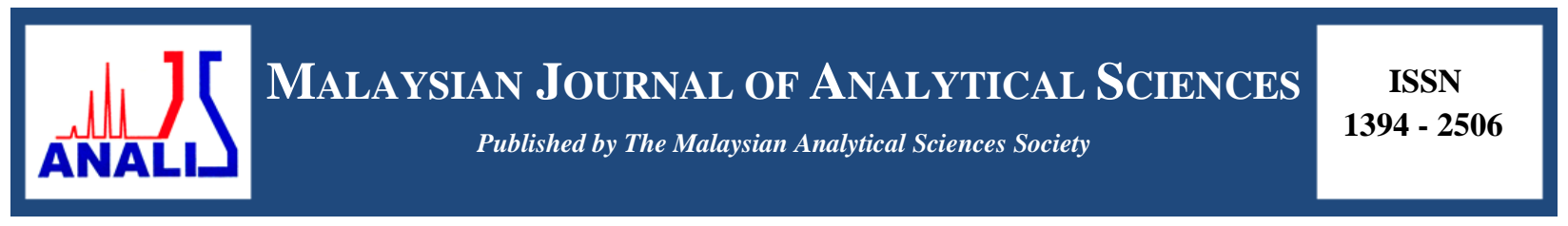

\title{
PENGGUNAAN KAEDAH PENYINARAN MIKROGELOMBANG DALAM SINTESIS TERBITAN TIOUREA
}

\section{(An application of Microwave Irradiation Technique in Preparation of Thiourea Derivatives)}

\author{
Hafizi Ahyak, Atisya Rohadi, Fatimatul Akma Awang Ngah, Bohari Yamin, Siti Aishah Hasbullah* \\ School of Chemical Sciences and Food Technology, \\ Faculty of Science and Technology, \\ Universiti Kebangsaan Malaysia, 43600 UKM Bangi, Selangor, Malaysia \\ *Corresponding author: aishah80@ukm.edu.my
}

Received: 22 January 2016; Accepted: 18 February 2016

\begin{abstract}
Abstrak
Sebatian baru terbitan tiourea, 1-etil-1-(2-hidroksi-etil)-3-naftalen-1-il-tiourea (3a) dan 1-(fenil-amino)-3-naftalen-1-il-tiourea (3b) telah berjaya disintesis melalui tindak balas antara 1-naftil isotiosianat (1) dengan etilena 2-etilaminoetanol (2a) dan fenilhidrazina (2b) menggunakan kaedah penyinaran mikrogelombang dan kaedah refluks. Peratusan hasil bagi kedua-dua kaedah yang digunakan untuk sebatian 3a dan 3b masing-masing adalah 3a (refluks: 66\%, mikrogelombang: 98\%) dan 3b (refluks: 72\%, mikrogelombang: 97\%). Hasil sintesis dianalisa dengan menggunakan alat spektroskopi FT-Inframerah (FT-IM), Spektroskopi Resonan Magnetik Nuklear (RMN) dan Spektrometri Jisim. Kajian antimikrob juga dilakukan dengan menggunakan Staphylococcus aureus dan Bacillus subtillus sebagai Gram positif, Escherichia coli dan Salmonella typhimurium sebagai Gram negatif dan kulat yang digunakan adalah Aspergillus niger. Kawalan positif yang digunakan adalah streptomisin dan kanamisin, manakala kawalan negatif yang digunakan adalah DMSO. Walaubagaimanapun hasil kajian mendapati tiada perencatan yang ketara terhadap pertumbuhan bakteria dan kulat (hanya 6-7mm kawasan perencatan) menggunakan sebatian tiourea ini.
\end{abstract}

Kata kunci: sebatian tiourea, mikrogelombang, aktiviti antimikrob

\begin{abstract}
New thiourea derivatives, 1-ethyl-1-(2-hydroxy-ethyl)-3-naphthalen-1-yl-iourea (3a), 1-(phenyl-amino)-3-naphthalen-1-ylTiourea (3b) have been synthesized from the reaction of naphthylisothiocyanate with 2-(ethylamino)ethanol (2a) and phenylhydrazine (2b) using microwave irradiation method. The percentage yield for both method used for compound $\mathbf{3 a}$ and $\mathbf{3 b}$, respectively 3a (reflux: 66\%, microwave: 98\%) and 3b (refluks: 72\%, mikrogelombang: 97\%). The compounds were analyzed by using Spectrometer FT-Infrared (FT-IR), Spectrometer Nuclear Magnetic Resonance (NMR) and Mass Spectrometry. Antimicrobial study was also conducted using Staphylococcus aureus and Bacillus subtillus as Gram positive, Escherichia coli and Salmonella typhimurium as Gram negative and fungi Aspergillus niger is used. The positive control used was streptomycin and kanamycin, while DMSO was used as the negative. However, this study shows no inhibition of bacteria and fungi (6-7mm of inhibition area) using these thiourea compounds.
\end{abstract}

Keywords: thiourea compound, microvawe, antimicrob activity

\section{Pengenalan}

Tiourea adalah sebatian organosulfur yang mempunyai formula $\mathrm{SC}\left(\mathrm{NH}_{2}\right)_{2}$. Struktur molekulnya sama seperti urea kecuali kedudukan oksigen digantikan dengan sulfur. Dalam satu kajian terbitan tiourea, kompleks poli(etilena 


\section{Hafizi et al: PENGGUNAAN KAEDAH PENYINARAN MIKROGELOMBANG DALAM SINTESIS TERBITAN TIOUREA}

glikol)-tiourea (PEG.TU) telah menunjukkan sifat mangkin dengan membantu tindak balas untuk menghasilkan produk dalam masa lebih singkat [1]. Selain itu, tiourea juga digunakan sebagai sumber sulfida di mana apabila bertindak balas dengan alkil halida, sebatian tiol dihasilkan. Tiourea juga telah banyak digunakan dalam kajian biologi sebagai racun serangga, racun rumput, anti-bakteria, anti-kulat, penawar penyakit paru-paru, antitiroid, dan pengatur pertumbuhan tumbuhan [2]. Terbitan tiourea juga merupakan blok binaan kimia yang penting dalam bidang kimia dan farmasi [3]. Terdapat juga kajian lepas yang membuktikan keberkesanan tiourea sebagai antimikrob. Tiourea juga mampu bertindak sebagai bahan antimikrob yang baik. Bahan tiourea yang mempunyai gelang benzotiazola mempunyai aktiviti antimikrob yang lebih tinggi berbanding tiourea tanpa gelang benzotiazola [4]. Selain itu, kajian tersebut juga mendapati kehadiran kumpulan pengganti nitro pada gelang benzotiazola dapat meningkatkan aktiviti antimikrobnya.

Sintesis sebatian tiourea dengan menggunakan kaedah refluks merupakan kaedah yang telah lama digunakan. Pada tahun 1940, penggunaan tenaga mikrogelombang dalam proses pemanasan makanan diperkenalkan. Kemudian, pada tahun 1950, inovasi dalam aplikasi teknikal seperti dalam bidang kimia dan industri telah diperkenalkan [5]. Kini dengan adanya kemajuan teknologi, sintesis sebatian ini sudah semakin diperbaharui dengan menggunakan kaedah mikrogelombang. Kaedah mikrogelombang ini bukan sahaja dapat menghasilkan produk dengan cepat, malah dapat meningkatkan ketulenan hasil berbanding kaedah konvensional [6]. Sintesis ini mengambil masa dua jam hingga semalaman [2]. Penggunaan mikrogelombang ini juga dikaitkan dengan konsep 'Kimia Hijau' kerana kaedah ini menggunakan tenaga mikrogelombang untuk tindak balas kimia [7]. Pada tahun 2012, satu kajian untuk sintesis sebatian N-fenil-4-(6-fenilimidazo[2,1-b]tiazol-5-il)tiazol-2-amina turut menggunakan kaedah mikrogelombang [8]. Peratusan produk yang terhasil adalah tinggi iaitu 89-95\%. Penggunaan mikrogelombang adalah mempercepatkan transformasi serta tindak balas bahan kimia organik $[9,10]$. Di dalam kajian ini, dua sebatian terbitan naftalentiourea (3a dan 3b) telah berjaya disintesis melalui bahan pemula amina, 2(etilamino)etanol (2a) dan fenilhidrazina (2b) melalui kaedah refluks dan kaedah mikrogelombang. Sifat antimikrobnya juga turut diuji dalam kajian ini.

\section{Bahan kimia}

\section{Bahan dan Kaedah}

Bahan-bahan kimia berserta pembekal yang digunakan dalam penyelidikan ini adalah 1-1-naftil isotiosianat (Acros), 2-(etilamino)etanol (Sigma Aldrich), fenil hidrazina (Sigma Aldrich), etilena diamina (Sigma Aldrich) dan pelarut organik seperti diklorometana, dimetilsulfoksida dan klorofom yang diperolehi dari syarikat Fisher. Semua bahan kimia dan pelarut digunakan tanpa perlu dilakukan proses penulenan terlebih dahulu.

\section{Instrumentasi}

Spektrum Infra Merah direkodkan menggunakan Perkin Elmer FT-IR pada suhu bilik. Sampel disediakan secara kaedah $\mathrm{KBr}$ dan dianalisis pada panjang gelombang $400-4000 \mathrm{~cm}^{-1}$. ${ }^{1} \mathrm{H}$ NMR and ${ }^{13} \mathrm{C}$ NMR spektrum direkodkan menggunakan spektrometer Bruker Advance (400 MHz) dan tetrametilsilana (TMS) sebagai rujukan. Kaedah pemisahan dan penulenan dilakukan menggunakan kaedah kromatografi lapisan nipis (KLN) di atas gel silika jenama Merck DC Kieselgel $60 \mathrm{~F}_{254}$.

\footnotetext{
Sintesis tiourea 1-etil-1-(2-hidroksi-etil)-3-naftalen-1-il-tiourea (3a) dan 1-(fenil-amino)-3-naftalen-1-iltiourea (3b)

Dalam kajian ini, penyediaan sebatian tiourea 1-etil-1-(2-hidroksi-etil)-3-naftalen-1-il-tiourea (3a) dan 1-(fenilamino)-3-naftalen-1-il-tiourea (3b) dilakukan dengan menggunakan dua kaedah, iaitu kaedah refluks dan kaedah mikrogelombang. Bagi sintesis sebatian (3a), 2-(etilamino)etanol (2a) $(0.179 \mathrm{~g}, 2.00 \mathrm{mmol})$ ditindak balaskan dengan 1-naftil isotiosianat (1) $(0.370 \mathrm{~g}, 2.00 \mathrm{mmol})$. Kedua-dua bahan pemula ini dimasukkan ke dalam kelalang dengan kehadiran pelarut diklorometana (DKM) sebanyak $10 \mathrm{ml}$. Kemudian, campuran tersebut dibiarkan refluks [11] selama semalaman. Setelah kajian kualitatif menggunakan kromatografi lapisan nipis (KLN) menunjukkan semua bahan telah bertindak balas, pelarut DKM akan disejat menggunakan penyejat berputar untuk mendapatkan hasil kasar.
}

Penyediaan sebatian (3a) menggunakan kaedah sinaran mikrogelombang bermula dengan mencampurkan bahan pemula, 2-(etilamino)etanol (2a) $(0.060 \mathrm{~g}, 0.667 \mathrm{mmol})$ dan 1-naftil isotiosianat (1) $(0.123 \mathrm{~g}, 0.667 \mathrm{mmol}) \mathrm{ke}$ dalam 
botol sampel dengan kehadiran pelarut DKM yang sedikit $(0.5 \mathrm{ml})$. Campuran tersebut disinarkan dengan mikrogelombang [12] pada 250W selama 5 minit. Mendakan putih terhasil dan ditentukan melalui analisis KLN.

Kedua-dua kaedah di atas diulangi dengan menggunakan fenilhidrazina (2b) $(0.216 \mathrm{~g}, 2.00 \mathrm{mmol})$ bagi menggantikan 2-(etilamino)etanol (2a) untuk penyediaan sebatian (3b). Kaedah konvensional yang digunapakai adalah kaedah tindak balas biasa iaitu tindak balas penambahan nuklofilik dan kaedah mikrogelombang adalah seperti yang telah dilaporkan oleh Atisya et al. [13].

(3a) Pepejal berwarna putih; takat lebur $114-116{ }^{\circ} \mathrm{C}$; FT-IM $\left(\mathrm{KBr}, \mathrm{cm}^{-1}\right) 3343,3291,1565,776 ;{ }^{1} \mathrm{H}$ NMR $(400$ $\mathrm{MHz}, \mathrm{DMSO}) \delta 1.23\left(3 \mathrm{H}, t, \mathrm{~J}=6.8 \mathrm{~Hz},-\mathrm{CH}_{3}\right), 3.76\left(2 \mathrm{H}, t, \mathrm{~J}=4.8 \mathrm{~Hz},-\mathrm{CH}_{2^{-}}\right), 3.82\left(2 \mathrm{H}, t, \mathrm{~J}=5.6 \mathrm{~Hz},-\mathrm{CH}_{2^{-}}\right), 3.86(2 \mathrm{H}$, $\left.q, \mathrm{~J}=6.8 \mathrm{~Hz},-\mathrm{CH}_{2^{-}}\right), 7.35(1 \mathrm{H}, m, \operatorname{Ar} H), 7.47(3 \mathrm{H}, m, \operatorname{Ar} H), 7.77(1 \mathrm{H}, m, \operatorname{Ar} H), 7.84(1 \mathrm{H}, m, \operatorname{Ar} H), 7.89(1 \mathrm{H}, m$, $\mathrm{ArH}), 9.43(1 \mathrm{H}, s,-\mathrm{NH}-) ;{ }^{13} \mathrm{C} \mathrm{NMR}\left(100 \mathrm{MHz}, d\right.$-DMSO) $\delta 12.9\left(\mathrm{CH}_{3}\right), 47.0\left(\mathrm{CH}_{2}\right), 53.0\left(\mathrm{CH}_{2}\right), 60.2\left(\mathrm{CH}_{2}\right), 124.0$ $\left(\mathrm{C}_{\mathrm{Ar}}\right), 124.6\left(\mathrm{C}_{\text {kuarternari }}\right), 126.3\left(\mathrm{C}_{\mathrm{Ar}}\right) 126.6\left(\mathrm{C}_{\mathrm{Ar}}\right), 128.0\left(\mathrm{C}_{\mathrm{Ar}}\right), 128.5\left(\mathrm{C}_{\mathrm{Ar}}\right), 131.1\left(\mathrm{C}_{\text {kuarternari }}\right), 134.1\left(\mathrm{C}_{\text {kuarternari }}\right), 134.3$ $\left(\mathrm{C}_{\mathrm{Ar}}\right) 138.0\left(\mathrm{C}_{\mathrm{Ar}}\right), 182.7(\mathrm{C}=\mathrm{S}) ; \mathrm{MS}(\mathrm{ESI}) \mathrm{m} / \mathrm{z} 297.08[\mathrm{M}+\mathrm{Na}]^{+}$.

(3b) Pepejal berwarna putih; takat lebur $189-193{ }^{\circ} \mathrm{C}$; FT-IM $\left(\mathrm{KBr}, \mathrm{cm}^{-1}\right) 3215,3169,1599,1545,759$; ${ }^{1} \mathrm{H}$ NMR (400 MHz, $d$-DMSO) $\delta 6.83(3 \mathrm{H}, m, \operatorname{Ar} H), 7.22(1 H, m, \operatorname{Ar} H), 7.38(3 \mathrm{H}, m, \operatorname{Ar} H), 7.74(4 \mathrm{H}, m, \operatorname{Ar} H), 7.81(4 \mathrm{H}, m$, $\mathrm{Ar} H), 9.53(1 \mathrm{H}, s,-\mathrm{N} H-), 9.87(1 \mathrm{H}, s,-\mathrm{N} H-) ;{ }^{13} \mathrm{C}$ NMR (100 MHz, $d$-DMSO) $\delta 113.3\left(\mathrm{C}_{\mathrm{Ar}}\right), 121.6\left(\mathrm{C}_{\mathrm{Ar}}\right), 123.8$ $\left(\mathrm{C}_{\mathrm{Ar}}\right), 126.7\left(\mathrm{C}_{\mathrm{Ar}}\right), 127.4\left(\mathrm{C}_{\text {kuarternari }}\right), 127.9\left(\mathrm{C}_{\mathrm{Ar}}\right), 128.2\left(\mathrm{C}_{\text {kuarternari }}\right), 128.5\left(\mathrm{C}_{\mathrm{Ar}}\right), 129.5\left(\mathrm{C}_{\text {kuarternari }}\right), 129.7\left(\mathrm{C}_{\mathrm{Ar}}\right), 130.8$ $\left(\mathrm{C}_{\mathrm{Ar}}\right), 134.5\left(\mathrm{C}_{\mathrm{Ar}}\right), 134.6\left(\mathrm{C}_{\text {kuarternari }}\right), 135.5\left(\mathrm{C}_{\mathrm{Ar}}\right), 183.3(\mathrm{C}=\mathrm{S}) ; \mathrm{MS}(\mathrm{ESI}) \mathrm{m} / \mathrm{z} 316.06[\mathrm{M}+\mathrm{Na}]^{+}$.

\section{Kajian antimikrob sebatian 3a dan 3b}

Aktiviti antimikrob diuji menggunakan kaedah penyebaran agar 'agar diffusion method' [14] dengan menggunakan Staphylococcus aureus dan Bacillus subtillus sebagai Gram positif, Escherichia coli dan Salmonella typhimurium sebagai Gram negatif dan kulat yang digunakan adalah Aspergillus niger. Kawalan positif yang digunakan adalah Streptomisin dan Kanamisin, manakala kawalan negatif yang digunakan adalah DMSO.

Stok sebatian tiourea yang telah disintesis disediakan dengan melarutkan $1 \mathrm{mg}$ sebatian tiourea ke dalam $1 \mathrm{ml}$ pelarut DMSO. Kemudian, $50 \mu \mathrm{l}$ dan $150 \mu \mathrm{l}$ dicairkan dalam kelalang isipadu $5 \mathrm{ml}$ untuk menghasilkan sebatian tiourea dengan kepekatan $10 \mu \mathrm{g} / \mathrm{ml}$ dan $30 \mu \mathrm{g} / \mathrm{ml}$ masing-masing. Sebanyak $10 \mu 1$ diambil dan diserapkan percakera sampel. Piring agar disebarkan mikrob dan dieramkan pada suhu $37^{\circ} \mathrm{C}$ selama 24 jam. Streptomisin, Kanamisin dan DMSO digunakan sebagai agen kawalan positif dan negatif ujian ini dengan menggunakan kaedah yang sama. Selepas 24 jam, diameter kawasan yang tidak ditumbuhi bakteria atau kulat sekitar cakera diukur untuk dibandingkan tahap aktiviti antimikrob dengan agen kawalan anti-bakteria yang digunakan $[14,15]$.

\section{Keputusan dan Perbincangan}

Sintesis terbitan tiourea telah berjaya dijalankan melalui tindak balas antara 1-naftil isotiosianat (1) dengan beberapa sebatian amina menggunakan kaedah konvensional iaitu kaedah refluks dan juga kaedah mikrogelombang. Tindak balas keseluruhan penghasilan tiourea ditunjukkan pada Rajah 1.

Merujuk kepada pencirian sebatian menggunakan spektroskopi infra merah, terdapat puncak pada $3343 \mathrm{~cm}^{-1}(\mathrm{OH})$ dan puncak pada $3291 \mathrm{~cm}^{-1}(\mathrm{NH})$ bagi sebatian 3a dan kehadiran regangan 3215 (NH 1) dan $3169 \mathrm{~cm}^{-1}(\mathrm{NH} 2)$ bagi sebatian 3b. Selain itu, ikatan C-N dapat dikenal pasti pada puncak $1565 \mathrm{~cm}^{-1}$ dan $1599 \mathrm{~cm}^{-1}$ bagi sebatian 3a dan 3b. Puncak ikatan $\mathrm{C}=\mathrm{S}$ pula dapat dilihat pada puncak $776 \mathrm{~cm}^{-1}$ dan $759 \mathrm{~cm}^{-1}$ bagi sebatian 3a dan 3b. Puncak ini adalah penting bagi menunjukkan pembentukan tiourea telah berlaku.

Pencirian ${ }^{1} \mathrm{H}$ NMR bagi sebatian 3a menunjukkan pada anjakan kimia 3.76 dan $3.82 \mathrm{ppm}$ puncak ini memberikan nilai integrasi 3.27 yang menunjukkan 3 proton $-\mathrm{CH}_{2}$ - yang merupakan hidrogen yang terikat kepada karbon pada bahagian etanol sebatian tersebut. Manakala pada anjakan kimia $3.86 \mathrm{ppm}$ pula merupakan proton pada ikatan $\mathrm{CH}_{2}$ - yang bersebelahan dengan $-\mathrm{CH}_{3}$. Ini dapat dibuktikan dengan kewujudan penggandaan spin quintet dengan nilai skala penggandingan $6.8 \mathrm{~Hz}$ pada anjakan kimia tersebut. Puncak yang penting adalah puncak bagi kumpulan amina yang terbentuk daripada tindak balas antara isotiosianat dan amina yang mana dapat dilihat pada pada anjakan kimia $9.43 \mathrm{ppm}$. Ini juga disokong oleh spektrum ${ }^{13} \mathrm{C}$ NMR yang menunjukkan terdapat pembentukan 


\section{Hafizi et al: PENGGUNAAN KAEDAH PENYINARAN MIKROGELOMBANG DALAM SINTESIS TERBITAN TIOUREA}

kumpulan $\mathrm{C}=\mathrm{S}$ yang dibuktikan melalui kehadiran puncak pada anjakan kimia pada $180.7 \mathrm{ppm}$. Bagi sebatian 3b pula, terdapat puncak pada anjakan kimia antara $6.83 \mathrm{ppm}$ dan $7.81 \mathrm{ppm}$ yang merupakan puncak bagi kumpulan aromatik. Pada anjakan kimia $9.87 \mathrm{ppm}$ dan $9.53 \mathrm{ppm}$ pula merupakan puncak bagi kumpulan amina. Hidrogen pada amina naftil dijangkakan memiliki anjakan kimia $9.87 \mathrm{ppm}$ manakala pada anjakan kimia $9.53 \mathrm{ppm}$ merupakan puncak pada amina hidrazina. Puncak yang terdapat pada nilai anjakan kimia $183 \mathrm{ppm}$ pula adalah karbon pada ikatan $\mathrm{C}=\mathrm{S}$, yang merupakan puncak yang utama bagi sebatian tiourea.

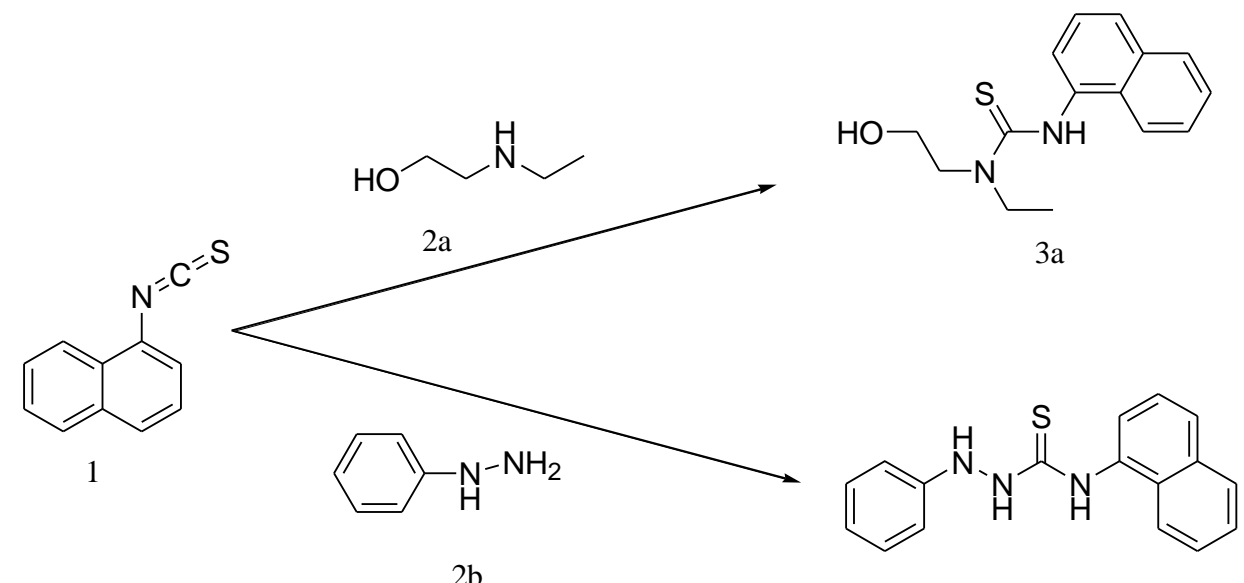

$3 b$

Rajah 1. Sintesis terbitan naftiltiourea 1-etil-1-(2-hidroksi-etil)-3-naftalen-1-il-tiourea (3a) dan 1-(fenil-amino)-3naftalen-1-il-tiourea $\mathbf{( 3 b )}$.

Spektrometri jisim menggunakan mod pengionan elektron (ESI) memberikan puncak sebatian 3a $(274.38 \mathrm{~g} / \mathrm{mol})$ bernilai $\mathrm{m} / \mathrm{z} 297.07$ merupakan puncak bagi molekul ion $[\mathrm{M}+\mathrm{Na}]^{+}$. Begitu juga bagi sebatian 3b yang mempunyai formula molekul $\mathrm{C}_{17} \mathrm{H}_{15} \mathrm{~N}_{3} \mathrm{~S}(293.39 \mathrm{~g} / \mathrm{mol})$ menunjukkan berat ion $[\mathrm{M}+\mathrm{Na}]^{+}$pada nilai $\mathrm{m} / \mathrm{z} 293.38$. Ion sodium sebagai ion molekul pseudo biasa digunakan bagi penentuan berat molekul menggunakan mod pengionan elektron. Jadual 1 di bawah menunjukkan peratusan hasil yang diperolehi daripada kaedah refluks dan kaedah mikrogelombang.

Jadual 1. Peratusan hasil kaedah refluks dan kaedah mikrogelombang

\begin{tabular}{ccc}
\hline \multirow{2}{*}{ Sebatian/ Kaedah } & \multicolumn{2}{c}{ Peratusan Hasil (\%) } \\
\cline { 2 - 3 } & Refluks & Mikrogelombang \\
\hline 3a & $66 \%$ & $98 \%$ \\
3b & $72 \%$ & $97 \%$ \\
\hline
\end{tabular}

Teknik mikrogelombang menghasilkan pemanasan dalaman yang lebih cekap disebabkan tenaga gelombang mikronya selari dengan molekul-molekul pelarut dan reagen yang terlibat dalam tindak balas. Maka masa tindak balas menjadi lebih cepat [7]. Jadual di atas membuktikan bahawa peratusan hasil daripada kaedah mikrogelombang adalah lebih tinggi berbanding dengan kaedah refluks. Hal ini kerana penggunaan teknik mikrogelombang dapat memberikan hasil tindak balas yang lebih bersih serta dapat mengurangkan pembentukan produk sampingan [16]. Melalui kaedah konvensional pula, peratusan hasil bagi sebatian 3a dan 3b adalah masing-masing $66 \%$ dan $72 \%$. Kaedah ini juga memerlukan masa yang lebih lama bagi suatu tindak balas lengkap. Hal ini disebabkan berlakunya 
pemindahan tenaga ke dalam sistem yang mana suhu luar lebih tinggi berbanding suhu di dalam campuran tindak balas [17]. Kebolehulangan tindak balas tidak dijalankan kerana kaedah mikrogelombang telah menghasilkan nilai peratusan yang kuantitatif.

\section{Aktiviti antimikrob}

Sebatian tiourea 3a dan 3b telah dicirikan dan ujikaji aktiviti antimikrobnya [14] telah dijalankan menggunakan antibiotik Streptomisin $(10 \mu \mathrm{g} / \mathrm{ml})$ dan Kanamisin $(30 \mu \mathrm{g} / \mathrm{ml})$ sebagai kawalan positif dan DMSO sebagai kawalan negatif. Jadual 2 dan Jadual 3 di bawah merupakan hasil daripada kajian yang telah dijalankan:

Jadual 2. Aktiviti antimikrob bagi sebatian terbitan tiourea dan antibiotik $(10 \mu \mathrm{g} / \mathrm{ml})$

\begin{tabular}{lccccc}
\hline Sebatian & \multicolumn{2}{c}{ Bakteria Gram positif $(\mathbf{m m})$} & Bakteria Gram negative (mm) & Kulat (mm) \\
\cline { 2 - 6 } & $\begin{array}{c}\text { Staphylococcus } \\
\text { aureus }\end{array}$ & $\begin{array}{c}\text { Bacillus } \\
\text { subtilis }\end{array}$ & $\begin{array}{c}\text { Escherichia } \\
\text { coli }\end{array}$ & $\begin{array}{c}\text { Salmonella } \\
\text { typhimurium }\end{array}$ & $\begin{array}{c}\text { Aspergillus } \\
\text { niger }\end{array}$ \\
\hline $\begin{array}{l}\text { Antibiotik streptomisin } \\
\text { 1-etil-1-(2-hidroksi- } \\
\text { etil)-3-naftalen-1-il- } \\
\text { tiourea (3a) }\end{array}$ & 16 & 17 & 16 & 19 & 10 \\
$\begin{array}{l}\text { 1-(fenil-amino)-3- } \\
\text { nftalen-1-il-tiourea } \\
\text { (3b) }\end{array}$ & 7 & 7 & 6 & 7 & 6 \\
\hline
\end{tabular}

Jadual 3. Aktiviti antimikrob bagi sebatian terbitan tiourea dan antibiotik $(30 \mu \mathrm{g} / \mathrm{ml})$

\begin{tabular}{|c|c|c|c|c|c|}
\hline \multirow[t]{2}{*}{ Sebatian } & \multicolumn{2}{|c|}{ Bakteria Gram positif (mm) } & \multicolumn{2}{|c|}{ Bakteria Gram negatif (mm) } & \multirow{2}{*}{$\begin{array}{c}\text { Kulat }(\mathbf{m m}) \\
\begin{array}{c}\text { Aspergillus } \\
\text { niger }\end{array}\end{array}$} \\
\hline & $\begin{array}{c}\text { Staphylococcus } \\
\text { aureus }\end{array}$ & $\begin{array}{l}\text { Bacillus } \\
\text { subtilis }\end{array}$ & $\begin{array}{c}\text { Escherichia } \\
\text { coli }\end{array}$ & $\begin{array}{c}\text { Salmonella } \\
\text { typhimurium }\end{array}$ & \\
\hline $\begin{array}{l}\text { Antibiotik } \\
\text { Kanamisin }\end{array}$ & 20 & 20 & 18 & 24 & 24 \\
\hline $\begin{array}{l}\text { 1-etil-1-(2- } \\
\text { hidroksi-etil)-3- } \\
\text { naftalen-1-il- } \\
\text { tiourea (3a) }\end{array}$ & 7 & 7 & 6 & 7 & 6 \\
\hline $\begin{array}{l}\text { 1-(fenil-amino)-3- } \\
\text { naftalen-1-il- } \\
\text { tiourea (3b) }\end{array}$ & 6 & 6 & 6 & 7 & 6 \\
\hline
\end{tabular}

Merujuk pada kedua-dua jadual di atas, aktiviti antimikrob yang dihasilkan oleh sebatian tiourea yang dihasilkan adalah sangat rendah. Keluasan kawasan yang mampu direncat pertumbuhan bakteria dan kulat adalah sekitar enam hingga tujuh milimeter diameter manakala antibiotik pula mampu untuk merencat pertumbuhan bakteria sejauh 10 hingga 24 milimeter diameter. Hasil menunjukkan terbitan tiourea yang dihasilkan tidak bersesuaian untuk dijadikan bahan antimikrob bagi bakteria-bakteria yang diuji. Kehadiran kumpulan penderma elektron atau kumpulan aromatik tanpa kumpulan pengganti penarik elektron menjejaskan aktiviti antimikrob sebatian berkenaan [15]. Sehubungan dengan itu, naftil tanpa kumpulan berfungsi penarik elektron dan kumpulan pengganti lain yang bertindak sebagai penderma elektron kepada kumpulan berfungsi tiourea akan memudaratkan aktiviti antimikrob 


\section{Hafizi et al: PENGGUNAAN KAEDAH PENYINARAN MIKROGELOMBANG DALAM SINTESIS TERBITAN TIOUREA}

tiourea tersebut. Selain itu, beberapa idea juga turut diketengahkan untuk meningkatkan keputusan perencatan bakteria oleh sebatian tersebut seperti meningkatkan kepekatan sebatian yang digunakan dalam merencatkan pertumbuhan mikrob. Terdapat juga cadangan untuk menggunakan kaedah lain yang berkemungkinan lebih efektif dalam menentukan aktiviti antimikrob ini seperti kepekatan perencatan asai minimum.

\section{Kesimpulan}

Sebatian 1-etil-1-(2-hidroksi-etil)-3-naftalen-1-il-tiourea (3a) dan 1-(fenil-amino)-3-naftalen-1-il-tiourea (3b) berjaya disintesiskan dengan menggunakan dua kaedah iaitu kaedah pemanasan secara refluks dan juga kaedah mikrogelombang. Hasil sebatian terbitan tiourea daripada kaedah mikrogelombang membuktikan bahawa peratusan hasil yang diperolehi adalah lebih banyak berbanding kaedah refluks. Jika dibandingkan pada faktor masa, kaedah mikrogelombang juga lebih cepat dan jimat kerana masa yang diperlukan untuk sintesis adalah singkat dan memerlukan pelarut yang paling minima $(0.5-1.0 \mathrm{ml})$.

\section{Penghargaan}

Kami ingin mengucapkan setinggi-tinggi penghargaan kepada pihak Pusat Pengajian Sains Kimia dan Teknologi Makanan (PPSKTM) Universiti Kebangsaan Malaysia, Pusat Pengurusan Penyelidikan dan Instrumentasi (CRIM), dan juga pihak yang terlibat dalam menjayakan penyelidikan ini. Kajian ini dijalankan dibawah geran penyelidikan FRGS/1/2015/ST01/UKM/02/2 dan PRGS/2/2015/SG01/UKM/02/1.

\section{Rujukan}

1. Sanny, V., Suman L. J. and Bir, S. (2010). PEG-embedded Thiourea Dioxide (PEG.TUD) as a Novel Organocatalyst for the Highly Efficient Synthesis of 3,4-dihydropyrimidinones. Tetrahedron Letters 51(52): $6897-6900$.

2. Arslan, H., Demet, S. M., Don, V. and Gun, B. (2009). The Molecular Structure and Vibrational Spectra of N(2,2-diphenylacetyl)-N'-(236aphthalene-1yl)-thiourea by Hartree-Fock and Density Functional Methods. Spectrochimica Acta Part A: Molecular and Biomolecular Spectroscopy 72(3): 561 - 571.

3. Alan R. Katritzky, N. K., Boris V. Rogovoy, J. K. and Tao, H. (2004). Synthesis of Mono- and N, NDisubstituted Thiourea and N-Acylthioureas. Heterocyclic: $1799-1805$.

4. Saeed, S., Naghmana, R., Peter G. J., Ali, M. and Hussain, R. (2010). Synthesis, Characterization and Biological Evaluation of Some Thiourea Derivatives Bearing Benzothiazole Moiety as Potential Antimicrobial and Anticancer Agents. European Journal of Medicinal Chemistry 45(4): 1323 - 1331.

5. Kappe, C. O. and Stadler, A. (2013). Microwaves in Organic and Medicinal Chemistry, John Wiley \& Sons.

6. Hayes, B. L. (2004). Recent Advances in Microwave Assisted Synthesis. Aldrichimica Acta 37(2): 66 -76.

7. Nguyen, Q. P. B. and Kim, T. H. (2013). Solvent- and Catalyst-free Direct Reductive Amination of Aldehydes and Ketones with Hantzsch Ester: Synthesis of Secondary and Tertiary Amines. Tetrahedron 69(24): 4938 4943.

8. Kamila, S., Kimberly, M. and Edward R. B. (2012). Microwave-assisted Hantzsch Thiazole Synthesis of Nphenyl-4-(6-phenylimidazo[2,1-b]thiazol-5-yl)thiazol-2-amines from the Reaction of 2-chloro-1-(6phenylimidazo[2,1-b]thiazol-5-yl)ethanones and Thioureas. Tetrahedron Letters 53(37): 4921 - 4924.

9. Gedye, R. N., Smith, F. E., Westaway, K. C., Ali, H., Baldisera, L., Laberge, L. and Rousell, J. (1986). The Use of Microwave Ovens for Rapid Organic Synthesis. Tetrahedron Letters 27(3): 279 - 282.

10. Giguere, R. J., Bray, T. L., Duncan, S. M. and Majetich, G. (1986). Application of Commercial Microwave Ovens to Organic Synthesis. Tetrahedron Letters 27(41): 4945 - 4948.

11. Khansari, M. E., Wallace, K. D. and Hossain, M. D. (2013). Synthesis and Anion Recognition Studies of Dipodal Thiourea-based Sensor for Anions. Tetrahedron Letters: 438 - 440.

12. Nguyen D. T. and Nguyen T. T. M. (2009). Synthesis of N-tetra-O-acetyl- $\beta$-D-glucopyranosyl-N'-(4',6'diarylpyrimidin-2'-yl)thioureas. Carbohydrate Research 344: 2399 - 2405.

13. Atisya, R., Hasbullah, S. A. Lazim, A. M., Nordin, R. (2014). Improving the synthesis of spiropyran derivatives using microwave irradiation method. Heterocycles 89(4):1017 - 1024.

14. Mohamed, N. A. and Abd El-Ghany, N. A. (2012). Preparation and antimicrobial activity of some carboxymethyl chitosan acyl thiourea derivatives. International Journal of Biological Macromolecules 50: $1280-1285$. 
15. Reddy, Y. T. and Reddy, P. N. (2005). Synthesis of 1-(6-methylbenzofuran-2-yl)-3-aryl/[44-( $\beta$ substitutedethoxy)phenyl]propenones as marked anti-microbial agents. Indian Journal of Chemistry 44:1079 1083.

16. Ravichandran, S. and Karthikeyan, E. (2011). Microwave synthesis - A Potential Tool for Green Chemistry. International Journal of ChemTech Research 3(1): 466 - 470.

17. Kappe, C. O. (2004). Controlled Microwave Heating in Modern Organic Synthesis. Angewandte Chemie International Edition 43: 6250 - 6284. 